Send your letters to the Editor, British

Dental Journal, 64 Wimpole Street, London

W1G8YS E-mail bdj@bda.org

Priority will be given to letters less than 500 words long. Authors must sign the letter,

which may be edited for reasons of space.

\section{Shot in the mouth}

Sir, we wish to report an unusual case. A 56-year-old woman presented recently complaining of pain in the lower right side of her mouth. This pain came on suddenly whilst eating roast pheasant the previous day. On examination there was a tender swelling in the gingivae overlying the edentulous alveolar ridge in the lower right quadrant.

The orthopantomogram radiograph taken showed a densely radiopaque circular foreign body in the soft tissues of the right posterior mandible (Fig. 1).

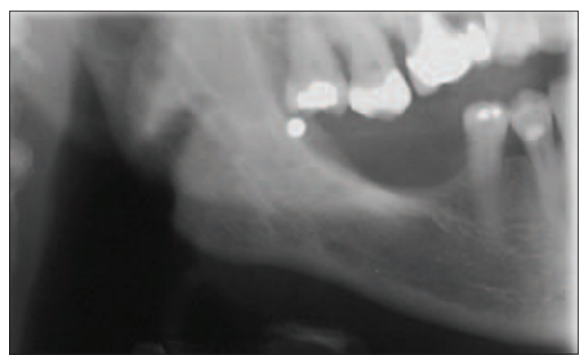

Fig. 1 An orthopantomogram showing a densely radiopaque circular foreign body in the soft tissues of the right posterior mandible region

The area was explored under local anaesthetic and lead shot removed. Evidently the lead shot had been freed from the pheasant meat on chewing and had then become lodged within the gingivae overlying the edentulous alveolar ridge. The dangers of lead ingestion from eating game are well described. However, to the best of our knowledge this is the first report of the lead shot becoming embedded within the gingival tissues.

B. Collard, S. Lee

P. Stimpson, L. Cascarini

London

DOI: 10.1038/bdj.2007.843

\section{Audacious amoxiclav}

Sir, please could someone explain why I am able to prescribe pethide, for which I cannot foresee a circumstance arising in which I would ever do so; yet I am unable to prescribe co-amoxiclav? A young patient recently presented with a severe dental infection, the tooth was opened, dressed and redressed with ledermix and amoxicillin but this failed to improve the situation. One of the indications for co-amoxiclav is severe dental infection. However, my attempt to do so resulted in my friendly local pharmacist kindly returning it to me after flashing lights and alarms were triggered on his computer by my audacious effort.

\section{J. Cooper}

By email

\section{Professor David Wray, Chair, BNF}

Dental Advisory Group responds: Thank you for the opportunity to respond to $\mathrm{Dr}$ Cooper's letter. The BDA appreciates the frustration of practitioners at not being able to prescribe on the NHS some medications necessary for optimum patient care. We have been trying for some years to gain greater access to the BNF for dentists prescribing on the NHS, and whilst this is a bit of an uphill battle we hope that it may become a reality in the future. The BDA advises the authors of the BNF through the BNF Dental Advisory Group (BNF DAG) and we recently requested that a number of additional medications be added to the Dental Practitioners Formulary list in the BNF. We are hopeful that these will be included in the next issue of the BNF.

Most dental infections, even severe ones, are usually due to Streptococci or gram negative organisms and so are usually sensitive to penicillin. If patients do not respond to amoxicillin alone, in severe infections, most clinicians would prescribe metronidazole in addition and this is usually successful.

Occasionally, infections may arise due to Staphylococci and, in these circumstances, prescription of flucloxacillin or co-amoxiclav would be appropriate. These are not on the list of additional medications we have already requested. However, we consider that it would be reasonable to include these on the Dental List and the BNF DAG will request that they are added. Currently patients with severe, unresponsive dental infections need referral to secondary care which has its own health economic implications. Alternatively a prescription can be given privately.

DOI: 10.1038/bdj.2007.844

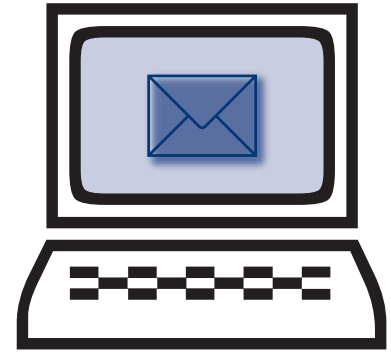

\section{Sugar - too sweet?}

Sir, despite the indisputable association between dietary sugars and dental caries, the intake of sugars has remained largely unchanged over the past 20 years. ${ }^{1}$ The Faculty of Public Health has recently launched its position statement on sugar. ${ }^{2}$ The final in the series of nutritional statements (along with fat and salt), Sugar - a position statement sets out the health dangers of too much sugar in the diet and what action should be taken to protect the public's physical and oral health.

The highly attractive sweetness of sugary foods and drinks can lead to over-consumption, with two main adverse effects on health:

- Overweight, obesity and increased risk of high blood pressure, diabetes and cardiovascular disease

- Dental plaque leading to dental caries, periodontal disease and halitosis.

An individual's intake of added sugars should provide less than $10 \%$ of total energy (calories) from food and drink. ${ }^{3}$ However, it has been reported that boys and girls have added sugar intake as high as $16.7 \%$ and $16.4 \%$ of total energy respectively. ${ }^{4}$ Such high intake of added sugars must not be ignored. Therefore a concerted effort is needed to reduce this figure.

I am delighted that the Faculty of Public Health are working in partnership with the British Dental Association and other organisations to push for more changes. These changes include:

- Increasing public awareness of the need to reduce sugar intake in food and drink, particularly for children

- Adopting a single, simple food labelling scheme by all food manufacturers and supermarkets, clearly stating levels of sugar

- Urging the food industry to reformulate products to use less sugar, and to offer a wider range of low sugar and sugar-free alternatives

- Improving standards, training and quality control in the catering industry on choosing ingredients and cooking methods to reduce sugar in meals 


\section{LETTERS}

AD 
- Reducing sugar in school meals, and meals provided by other social catering outlets such as hospitals and care homes

- Imposing effective restrictions on advertising sugary snacks to children

- Continuing to promote the 5-a-day message and to improve access to good quality, affordable fresh fruit and vegetables.

\section{A. Yeung}

\section{Manchester}

1. Rugg-Gunn A J, Fletcher E S, Matthews J N S et al. Changes in consumption of sugars by English adolescents over 20 years. Public Health Nutr 2007; 10: 354-363

2. Faculty of Public Health. Sugar - a position statement. London: Faculty of Public Health, 2007. http:// www.fph.org.uk/resources/Atoz/ps_sugar.pdf

3. World Health Organization/Food and Agriculture Organization. Diet, Nutrition and the Prevention of Chronic Diseases. Report of the Joint WHO/FAO Expert Consultation. WHO Technical Report Series, no. 916. Geneva: World Health Organization \& Food and Agriculture Organization, 2003.

4. British Nutrition Foundation. Nutrition basics: energy and nutrients - carbohydrate. London: British Nutrition Foundation, 2004. http://www.nutrition.org.uk/home. asp?siteld $=43$ \& tsectionld $=608$

\section{DOI: 10.1038/bdj.2007.845}

\section{Lack of clarity}

Sir, I believe that there is still a lack of clarity in some quarters as to procedural matters related to the appointment of consultants. I think it would be helpful to update this as outlined in current regulations and available on: http:// www.dh.gov.uk/en/Publicationsandstatistics/Publications/PublicationsPolicyAndGuidance/DH_4102748.

The National Health Service (Appointment of Consultants) Amendment Regulations 2004 states that 'accredited as a consultant' means: (a) a person whose name is included in the register of specialists maintained by the General Medical Council pursuant to article 8 of the European Specialist Medical Qualifications Order 1995 (the specialist register); or (b) a person whose name is included in the register of specialists maintained by the General Medical Council pursuant to article 13 of the General and Specialist Medical Practice (Education, Training and Qualifications) Order 2003 (the specialist register).

A consultant is required to be a medical or dental practitioner, although the SI makes no mention of a specific requirement to be on the Dentists Register. The regulations apply to NHS trusts, primary care trusts and strategic health authorities, but the 1996 Regulations and subsequent amendments do not apply to NHS Foundation Trusts - although they can follow this guidance when appointing to a consultant post if they so choose.
In general, the consultant post must be advertised with a minimum of two advertisements, at least one in a printed journal (undefined); and in general the person is interviewed at an Advisory Appointments Committee (AAC). Exempt from the latter are persons who receive no remuneration from the (NHS) Authority (Health Authority) and are members of academic staff of a university, as well as a number of other categories.

The job description is the focus of most attention and needs consultation with relevant bodies. Trusts should consult the Regional Adviser (RA) of the relevant Royal College or Faculty (only English ones are named) and the roles of the Adviser are defined and have limitations. Where an employer chooses not to accept the RA's advice, they may wish to raise the matter with the College President but this will not prevent an employer advertising the post. In Trusts where there is a significant teaching commitment, the Trust should liaise with the university through the dental school dean. As stated, the 1996 Regulations and subsequent amendments do not apply to NHS Foundation Trusts.

The regulations outline the constitution of the AAC as being of a minimum of six people; a lay member (defined in the SI); an external professional assessor appointed after consultation with the relevant college or faculty; the chief executive of the appointing body; the medical or dental director of the Trust; a consultant from the Trust, preferably in the relevant specialty; and, where the post involves substantial teaching or research, a further professional member appointed after consultation with the relevant university. All AAC members should have received appropriate training. Business cannot be conducted in the absence of a core member or deputy, and there must be due cognisance of issues related to Equal Opportunities, the Disability and Discrimination Act, Race Relations Act, Sex Discrimination Act and other relevant legislation and Codes of Practice. A majority decision is required before the applicant can be considered suitable for appointment.

\section{Scully \\ London}

DOI: 10.1038/bdj.2007.846

\section{Search for truth}

Sir, in your guest editorial (BDJ 2007; 203: 1) the Chairman of the British Orthodontic Society Ethics Committee, Joe Noar, drew attention to the difficult problem of establishing an ethical balance between conventional and novel orthodontic techniques. He mentioned 


\section{LETTERS}

$\mathrm{AD}$ 
the marathon case bought by the GDC against a dentist who genuinely believed in unorthodox orthodontic care. This caused huge emotional and professional distress to the dentist indicted, and many felt this case should never have been pursued.

Having pressed for and achieved specialisation, the orthodontic specialty in the UK has established itself in a very powerful position and there is now great uniformity in the patterns of treatment taught at British universities which some might think unhealthy. The General Dental Council have in my view made the error of supporting this singular stance although their foundation requires them to prevent any 'dental authority ... imposing ... or refraining from ... any particular theory of dentistry...' Currently regardless of their training and experience general dentists are not allowed to claim any special knowledge of orthodontics unless they are registered as specialists with the Council.

The Ethics committee of the British Association of Orthodontists supported by the GDC - with whom they have established a close relationship - currently advise their members that they need not inform patients about nonorthodox methods of treatment. This leaves many patients unaware that someone else might offer them a nonextraction or non-surgical solution to their problem. In effect the orthodontists are making this decision on behalf of the patient because they believe unorthodox methods are inappropriate.

Certain knowledge is a rare thing and the orthodontic establishment might find it difficult to justify such a claim at the moment. There is as yet no consensus on the cause of irregular teeth making it difficult to balance any particular cure. It is this uncertainty that has caused many dissatisfied dentists to search for more effective cures and there are now many groups around the world using alternative treatment concepts, none of which should, in fairness, be dismissed out of hand. We just do not have the evidence to say that any method is right or wrong.

I think established orthodontists should be careful about claiming special rights. I do not know of one long-term study showing that any orthodontic treatment has bestowed significant benefits to patients. Add to that the known iatrogenic side effects and it might be hard to justify their treatment before a NICE committee at all.

While there can be many opinions there can be but one truth; how can we find it? In the past I have seen many wise gatherings fail in their attempts to achieve scientific consensus. This is usually because the different lobby groups persist with their claims, resulting in a hardening of opinions rather than the reverse. I have suggested several times to both the GDC and BOS that the best way to resolve this problem is for each group to present their evidence before an independent jury of scientific experts who have no special knowledge of the subject themselves and are therefore without prejudice. The Chartered Institute of Arbitrators are prepared to provide the jury; are we prepared to accept their verdict? Only when someone does something will anything happen.

\section{J. Mew}

By email

DOI: 10.1038/bdj.2007.847

\section{Salivary sialoliths}

Sir, sialoliths are the most common condition of salivary glands and account for more than $50 \%$ of major salivary gland disease. They are usually round or ovoid, but rarely have large stones such as the one below been described. A 58year-old man presented with a three day history of pain and swelling in the right side of his neck and the right floor of his mouth with no previous symptoms. On examination a firm, non-tender mass on the floor of his mouth was noted as well as a tender right sub-mandibular salivary gland.

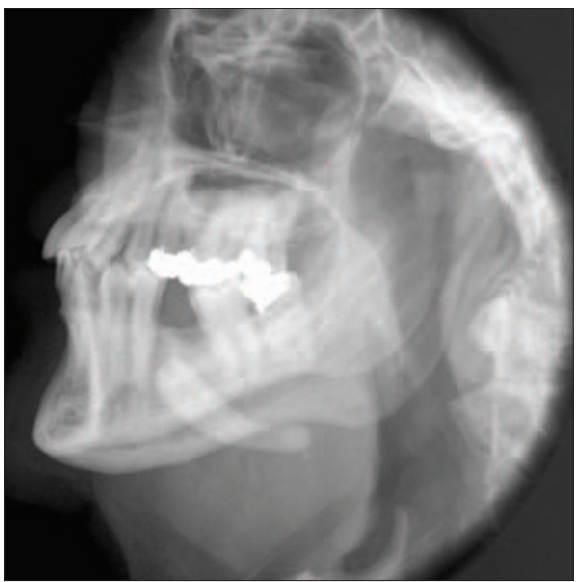

Fig. 1 Sialolith involving the entire length of the submandibular gland duct

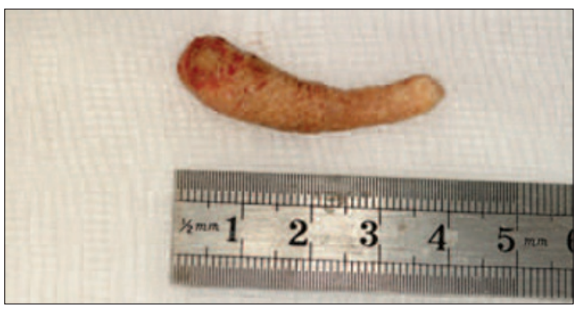

Fig. 2 The removed sialolith
A radiograph revealed a large calcified mass, extending from the hilum to the opening of the duct (Fig. 1), suggesting an unusually large sialolith. The sub-mandibular gland and the sialolith were subsequently removed. The photograph shows the $4 \mathrm{~cm} \times 1 \mathrm{~cm}$ calculus (Fig. 2). The histopathology of the removed gland shows chronic sialedenitis with fatty changes and squamous metaplasia of the duct itself.

Although the incidence of sialoliths in the submandibular ducts is quite common, the appearance of large sialoliths such as the one described are rare. Despite the three day symptomatic history, the long term effect of the sialolith on the gland itself is shown by the histological changes, suggesting the asymptomatic presence of the mass for a considerable time. Sialoliths such as these require removal of the stone as well as the associated gland.

\section{Shah, S. Shetty}

By email

DOI: $10.1038 / b d j .2007 .848$

\section{A paucity of cases}

Sir, we read with interest the paper by $\mathrm{E}$. Thomas (BDJ 2007; 203: 33-34) reporting lip adhesions following primary herpetic gingivostomatitis. The ability of primary herpes infections to result in genital adhesions is well recognised. ${ }^{1}$ However, there is a paucity of well documented cases of lip adhesions occurring considering the frequency with which this infection occurs. We are aware, however, of several reports of lip adhesions following erythema multiforme and Stevens-Johnson syndrome, including cases in children of a similar age to that described in the paper. ${ }^{2-4}$ At times, clinical differentiation of erythema multiforme and acute herpetic gingivostomatitis can be difficult, and we note that the diagnosis of herpetic infection was based on clinical criteria alone. In such cases, erythema multiforme also needs to be considered as the possible original diagnosis.

M. N. Pemberton

B. P. Rajlawat

By email

1. Herieka E, Dhar J. Labial adhesions following severe primary genital herpes. Sex Transm Infect 2001; 77: 75.

2. Sakamoto $H$, Nagashima T, Imai Y. Angular webbing associated with Stevens-Johnson syndrome. Int J Oral Maxillofac Surg 1993; 22: 118.

3. Marinho L H M, Haj M, Pereira L F M. Lip adhesion: an unusual complication of erythema multiforme. Oral Surg Oral Med Oral Pathol Oral Radiol Endod 1999; 88: 167-169.

4. Anwar M U, Foo I F. An unusual sequelae of Stevens-Johnson Syndrome. Int J Oral Maxillofac Surg 2006; 35: 975-976.

DOI: 10.1038/bdj.2007.849 